05

\title{
Механизм и динамика разрушения поверхности напряженных гранитов под влиянием ударной волны
}

\author{
(ㄱ И.П. Щербаков, В.И. Веттегрень, Р.И. Мамалимов, Х.Ф. Махмудов \\ Физико-технический институт им. А.Ф. Иофрфе РАН, \\ 194021 Санкт-Петербург, Россия \\ ฯ e-mail: Victor.Vettegren@mail.ioffe.ru
}

(Поступило в Редакцию 30 октября 2017 г.)

$\mathrm{C}$ временным разрешением $2 \mathrm{~ns}$ исследована динамика вылета положительно заряженных ионов под влиянием ударной волны с поверхностей гранитов, содержащих различную концентрацию кварца и полевого шпата. Предполагается, что ионы вылетают в моменты выхода на поверхность образца дислокаций, двигающихся в пересекающихся плоскостях скольжения. На месте выхода дислокаций образуются дефекты, которые имеют вид протяженных „канавок“. Сжимающая нагрузка подавляет процесс образования дефектов.

DOI: 10.21883/JTF.2018.07.46168.2537

\section{Введение}

В последние годы нами были начаты экспериментальные исследования механизма и динамики разрушения с наносекундным разрешением ненагруженных и одноосно сжатых горных пород под воздействием ударных волн [1-7]. Интерес к этой проблеме вызван тем, что скорость ударной волны в несколько раз больше скорости поперечной звуковой волны $S_{t}$, а разрушение путем образования и накопления трещин может происходить только со скоростью, не больше чем $\sim 1 / 3 S_{t}[8]$. В наших исследованиях было установлено [1-7], что кристаллические решетки кварца и полевых шпатов, входящих в состав гранитов, под воздействием ударных волн разрушаются не путем образования и накопления микротрещин, а испарением с вылетом положительно заряженных ионов и электронов.

В настоящей работе исследована динамика разрушения одноосно сжатых гранитов, концентрация кварца в которых изменялась от нуля до 35-40\%. Предполагалось, что изменение концентрации кварца может повлиять на динамику разрушения гранитов.

\section{Объект и метод исследования}

Для исследований были использованы граниты трех видов: аляскит, плагиогранит и габбро-диабаз. Аляскит и плагиогранит содержали зерна кварца $(\sim 35-40 \%)$ и полевого шпата - плагиоклаза $(\sim 50-60 \%)$. Средний размер зерен этих минералов в аляските составлял $\sim 7 \mathrm{~mm}$, а в плагиограните - $4 \mathrm{~mm}$. Габбро-диабаз состоял из плагиоклаза $(\sim 60 \%)$ и пироксена $(\sim 30 \%)$ с размерами зерен $\sim 2 \mathrm{~mm}$.

Из гранитов были выпилены образцы в виде параллелепипедов с размерами ребер $4 \times 4 \times 6 \mathrm{~cm}$. Внутри них был вырезан паз, в который были вставлены медные электроды, присоединенные к конденсатору. При разряде конденсатора между электродами возникала дуга. Она вызывала появление ударной волны в воздухе и вслед за ней — в образце [9]. Энергия разряда составляла $\sim 0.2 \mathrm{~J}$, а мощность $-2 \cdot 10^{5} \mathrm{~W}$.

Вылетающие из гранитов ионы находятся в электронно-возбужденном состоянии. При переходе из возбужденного в основное состояние они излучают свет в видимой области спектра, т.е. возникает люминесценция. Для ее регистрации перед поверхностью образцов устанавливали один из концов кварцевого световода, а его второй конец располагали перед поверхностью фотокатода фотоэлектронного умножителя PMT-136 (рис. 1). Напряжение на выходе РМТ подавали на вход аналого-цифрового преобразователя ADS-3112 и через каждые $2 \mathrm{~ns}$ записывали в память компьютера для дальнейшего анализа и обработки.

Для сжатия образцов использовали пресс PGDR. Величину сжимающего напряжения изменяли ступенчато - через 10-20 МРа. После приложения заданного напряжения через образец пропускали ударную волну и записывали временную зависимость интенсивности люминесценции.

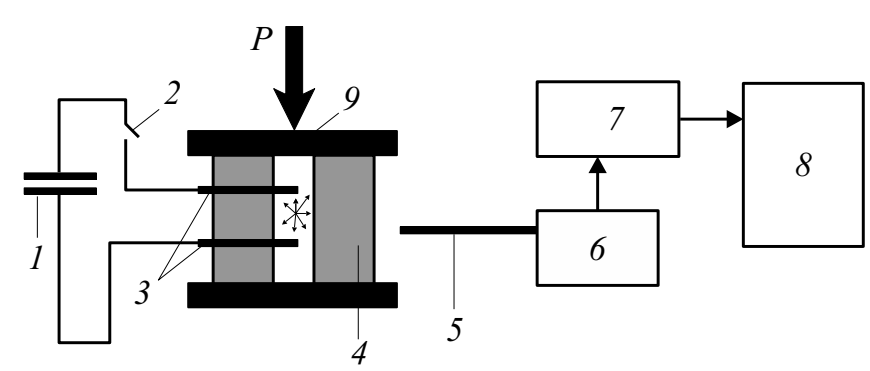

Рис. 1. Блок-схема установки: 1 - конденсатор, 2 - электронный ключ, 3 - электроды (между которыми происходит электрический пробой), 4 - образец, 5 - кварцевый световод, 6 - фотоумножитель РЕМ-136, 7 - аналого-цифровой преобразователь ADS-3112, 8 - компьютер, 9 - пресс. 
Характеристики распределения числа струй ионов, вылетающих из ненапряженных и сжатых образцов гранитов, от их интенсивности $I_{m}$

\begin{tabular}{l|c|c|c|c|c}
\hline \multirow{2}{*}{ Гранит } & Прочность, МРa & $\begin{array}{c}\text { Размер зерен } \\
\text { плагиоклаза, } \mathrm{mm}\end{array}$ & $\begin{array}{c}\text { Сжимающее } \\
\text { напряжение, MРa }\end{array}$ & $\ln N_{0}$ & $b \cdot 10^{3}$ \\
\hline \multirow{2}{*}{ Аляскит } & \multirow{2}{*}{160} & 6.5 & 0 & 3.2 & 3 \\
\hline \multirow{2}{*}{ Габбро-диабаз } & \multirow{2}{*}{320} & 2 & 144 & 2.8 & 5 \\
\cline { 3 - 7 } & & & 210 & 2.7 & 10 \\
\end{tabular}

\section{Механизм образования люминесценции}

Через $\sim 23 \mu$ s после замыкания пластин конденсатора происходила ионизация молекул воздуха, и затем возникал пробой промежутка между электродами. Еще через $\sim 0.3 \mu$ s загоралась дуга (рис. 2). Интенсивность ее излучения достигала максимального значения через $\sim 0.6 \mu \mathrm{s}$, а затем уменьшалась приблизительно экспоненциально от времени. Через $\sim 2.6 \mu$ s после возникновения пробоя интенсивность дуги уменьшалась на порядок.

На рис. 3 показаны спектры люминесценции аляскита и плагиогранита, полученные при энергии разряда $80 \mathrm{~J}$. Они состоят из нескольких десятков узких (шириной $\sim 0.5-1 \mathrm{~nm})$ линий, наложенных друг на друга. Воспользовавшись таблицами спектральных линий [10], установлено, что они соответствуют излучению положительно заряженных ионов. В соответствии с составом аляскита в спектре его люминесценции наблюдали излучение одно, двух и трех положительно заряженных ионов $\mathrm{Na}, \mathrm{Fe}, \mathrm{Si}, \mathrm{Al}$ и $\mathrm{O}$, а в спектре плагиогранита - $\mathrm{Al}$, $\mathrm{Ca}, \mathrm{K}, \mathrm{Li}, \mathrm{Na}, \mathrm{Fe}, \mathrm{O}$ и Mn. Кроме того, в спектрах содержались линии, соответствующие ионам азота и меди. Ионы азота образовались при ударе ионов плазмы о молекулы азота воздуха, а ионы меди вылетели из медных электродов.

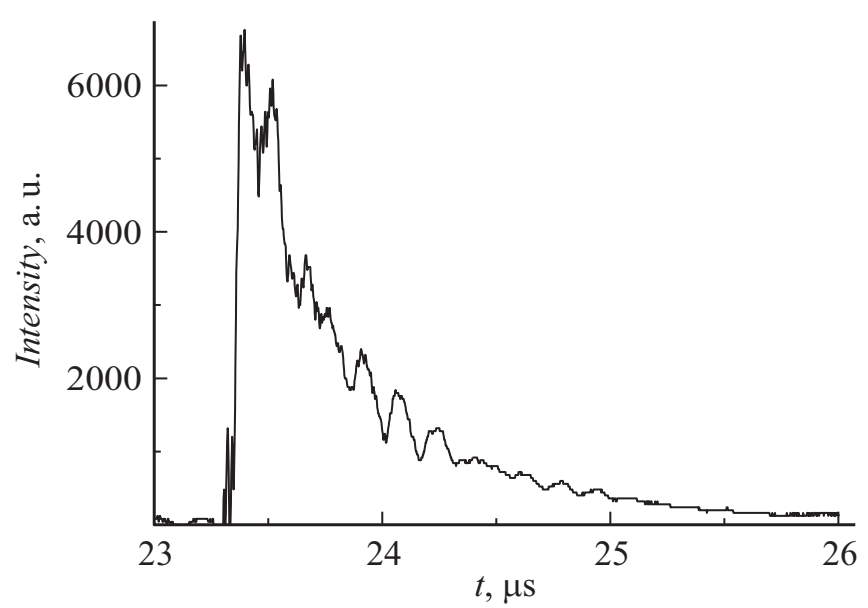

Рис. 2. Временная зависимость интенсивности дуги.
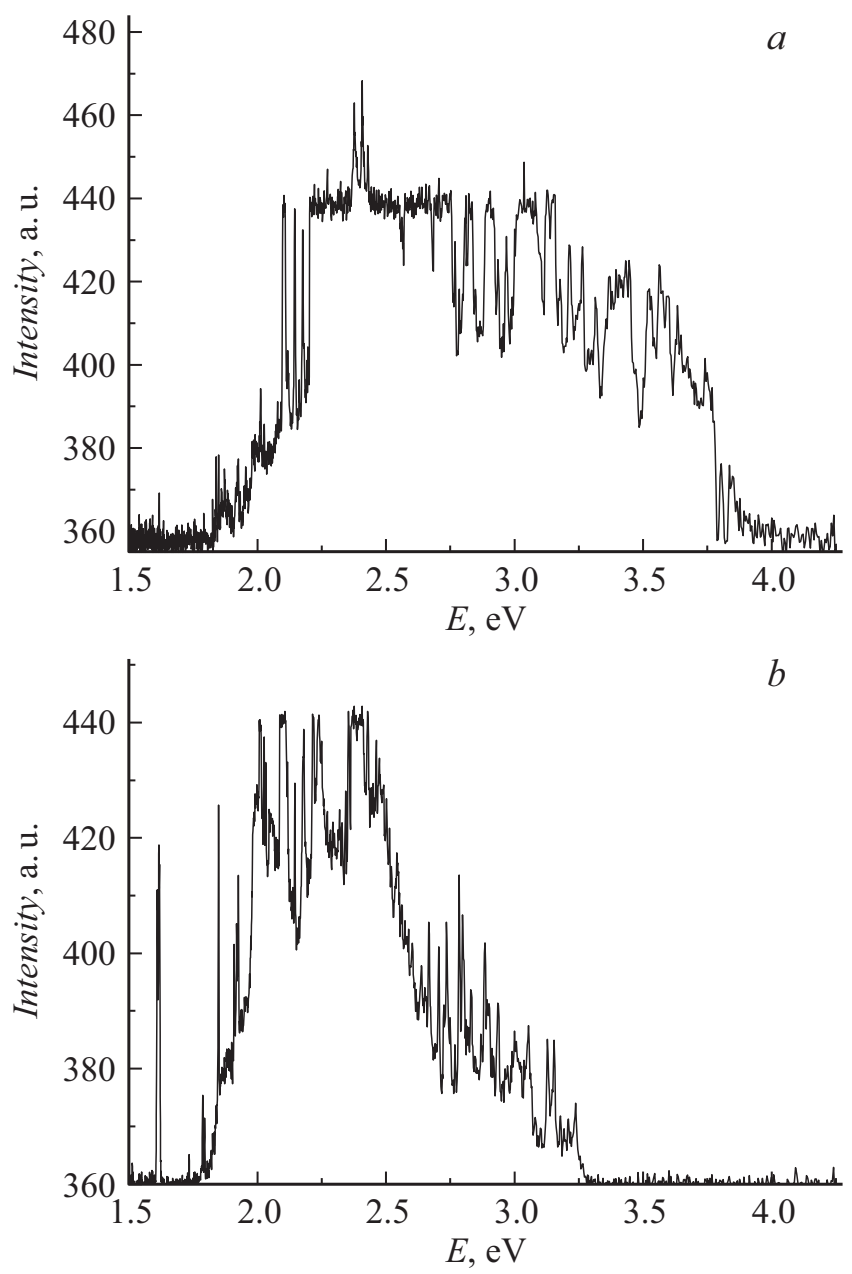

Рис. 3. Спектры люминесценции плагиоклаза $(a)$ и аляскита $(b)$.

Эти результаты показывают, что ударная волна вызывает разложение гранитов, при котором с их поверхности вылетают положительно заряженные ионы. При энергии разряда $80 \mathrm{~J}$ около $80 \%$ объема образца распадается на ионы.

Уменьшим теперь энергию разряда в 400 раз до 0.2 J. Оказалось, что при такой энергии из гранита тоже вылетают ионы (рис. 4). В этом случае они пред- 
ставляют собой струи, интенсивность которых варьирует на $\sim 2$ порядка, а интервал между ними изменяется от нескольких десятков ns до нескольких $\mu \mathrm{s}$.

Каков же механизм образования ионов? Известно [11], что при взаимодействии дислокаций, движущихся в пересекающихся плоскостях скольжения, возникают сильные искажения кристаллической решетки. Они могут вызывать переходы между уровнями основного и возбужденного электронных состояний и распад межатомных связей. Ударная волна „выносит“ искаженные участки кристаллических решеток на поверхность, что и приводит к вылету возбужденных положительно заряженных ионов.

Известно, что искажения кристаллической решетки в местах пересечения плоскостей скольжения препятствуют движению дислокаций. Поэтому около таких пересечений скапливаются цуги из нескольких десятков-сотен дислокаций [12]. При их прорыве на поверхности должны появляться дефекты в виде канавок, глубина которых может достигать $\sim 1 \mu \mathrm{m}$ и более. Такие дефекты должны наблюдаться в оптический микроскоп.
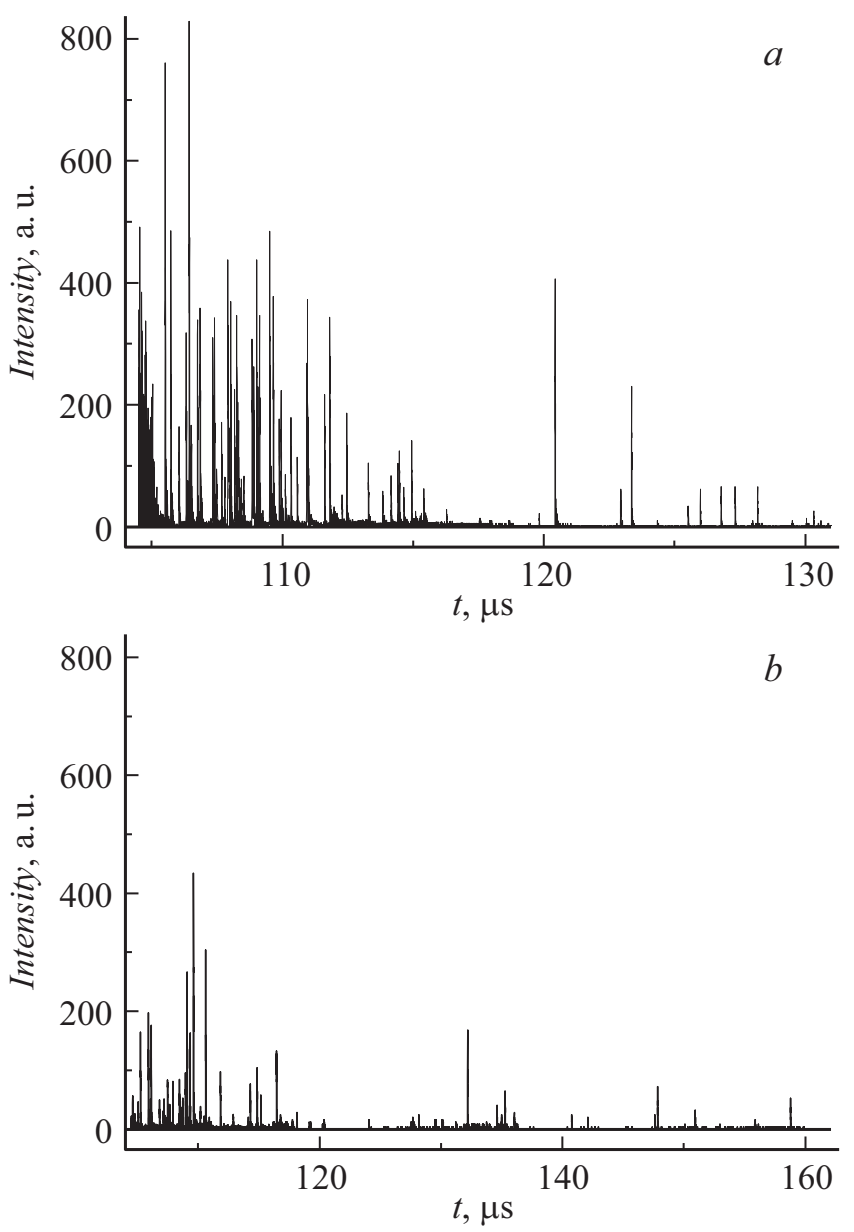

Рис. 4. Временные зависимости интенсивности струй ионов, вылетающих из габбро-диабаза. Сжимающее напряжение, МРа: $a-0 ; b-208$.

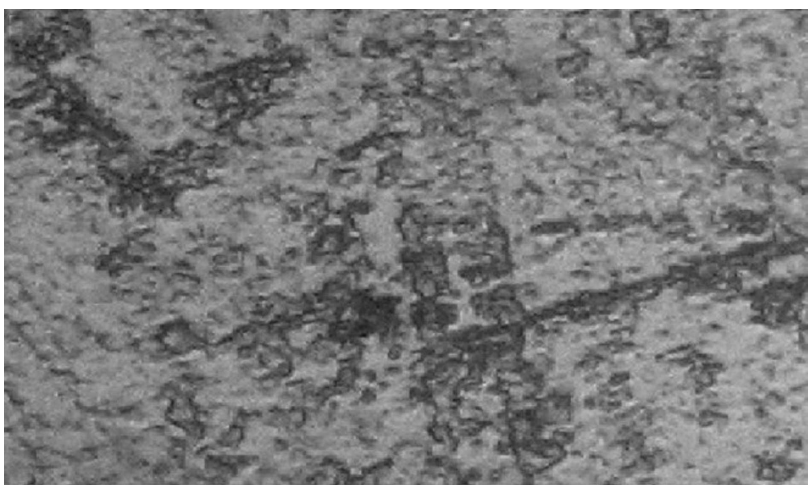

$a$

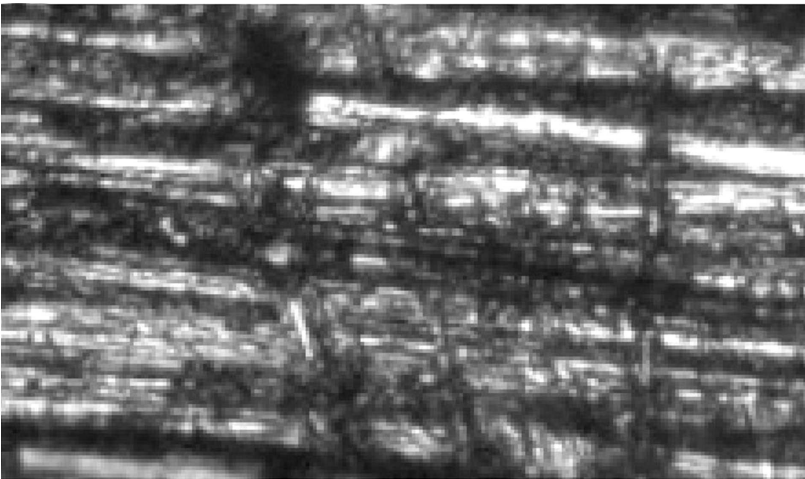

$b$

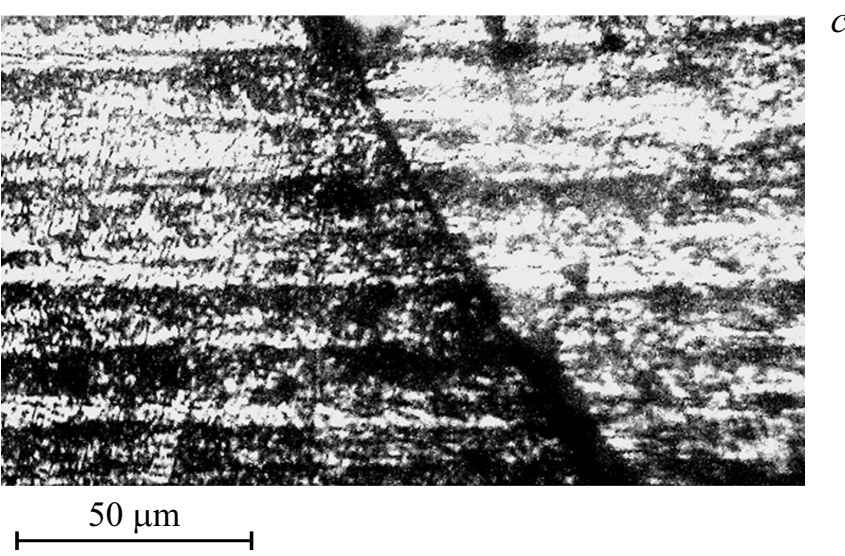

Рис. 5. Фотографии поверхности аляскита (a) до воздействия ударной волны, аляскита $(b)$ и габбро-диабаза $(c)$ после ее воздействия. Темная наклонная полоса на рисунке $(c)-$ граница между зернами габбро-диабаза.

Оказалось, что, действительно, после воздействия ударной волны на поверхностях гранитов наблюдаются дефекты, имеющие вид протяженных „канавок“ (рис. 5).

\section{Динамика разложения гранитов}

Вернемся вновь к рассмотрению рис. 4, на котором показаны временные зависимости интенсивности струй ионов, вылетающих из габбро-диабаза и аляскита под действием ударной волны. Такие же временные зависимости интенсивности струй ионов наблюдались ранее для плагиогранита [6]. Во всех случаях увеличение 

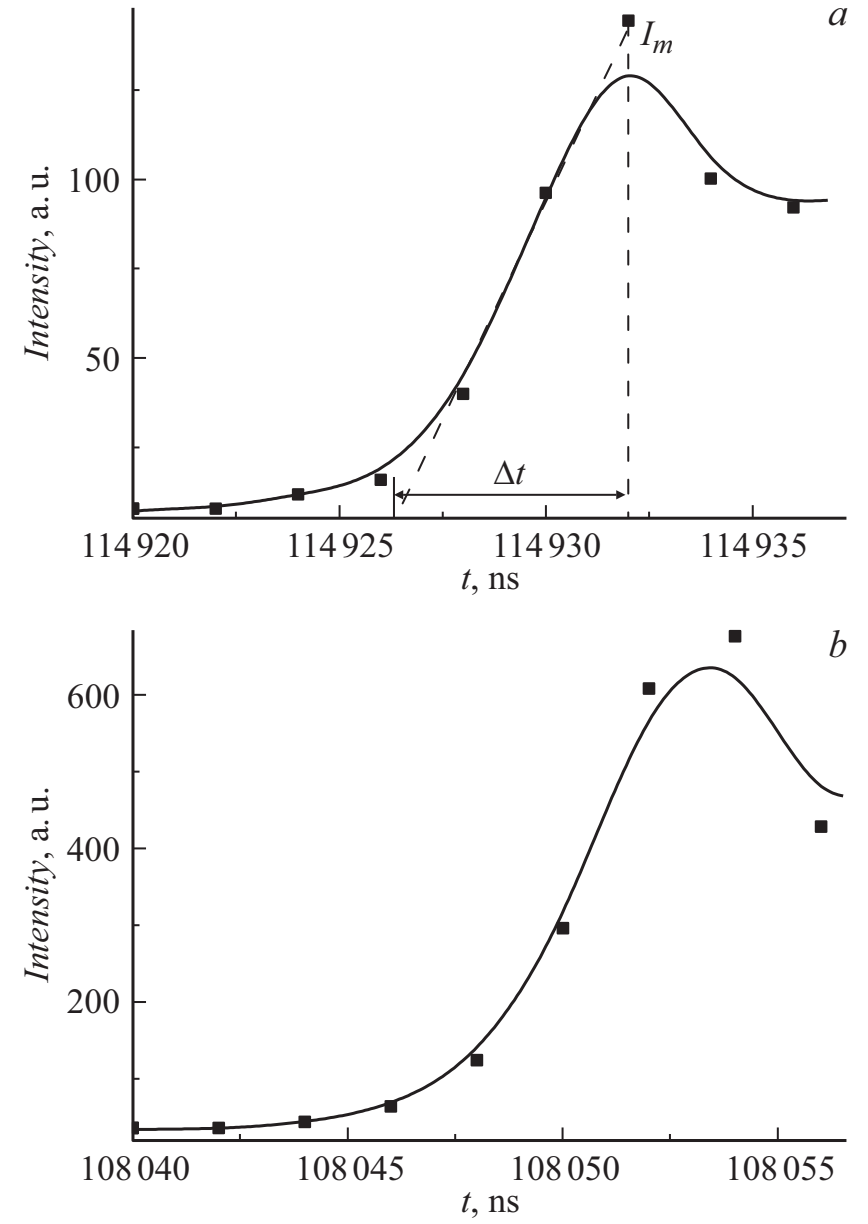

Рис. 6. „Одиночные“ струи ионов из аляскита. Давление, МРа: $a-0 ; b-144$.

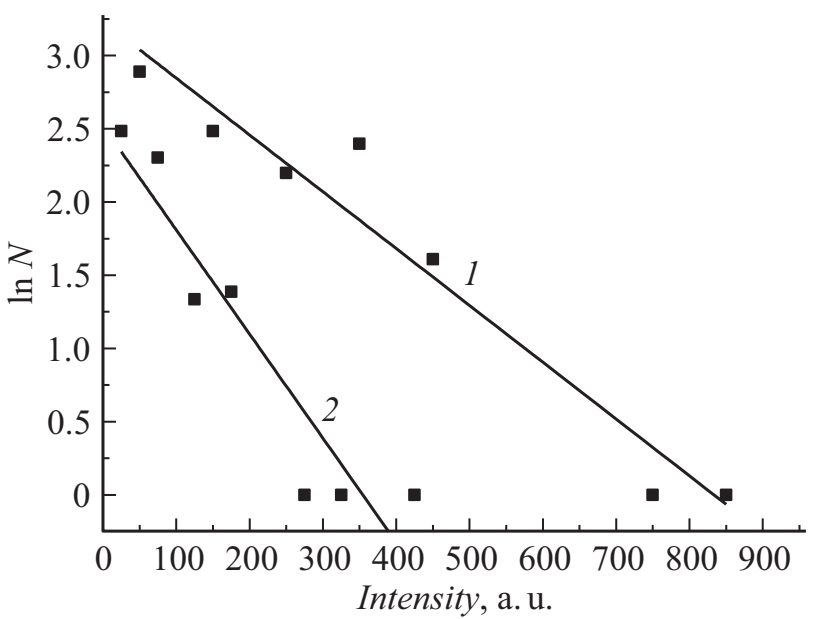

Рис. 7. Зависимости числа струй ионов от их интенсивности для габбро-диабаза. Давление, МРа: $1-0 ; 2-210$.

сжимающего напряжения приводило к уменьшению числа струй. Это показывает, что сжимающее напряжение препятствует выходу цугов дислокаций на поверхность.
На рис. 6 показаны фрагменты временных зависимостей сигнала от РЕМ при образовании одной из канавок. Видно, что интенсивность сигнала сначала растет, достигает максимального значения и затем уменьшается. Величина интенсивности определяется скоростью двух процессов. Первый - рост интенсивности при образовании „канавки“. Второй - уменьшение сигнала от РЕМ после ее образования. Скорость такого уменьшения определяется величинами паразитной емкости и сопротивления нагрузки.

Будем полагать, что максимальная скорость роста интенсивности струй ионов задана скоростью ударной волны. В гранитах она составляет $\sim 5 \mathrm{~km} / \mathrm{s}$ [2]. Тогда по времени $\Delta t$ достижения максимального значения интенсивности $I_{m}$ струй (рис. $6, a$ ) можно оценить длину дефектов. Оказалось, что для всех исследованных гранитов она варьирует от $\sim 5$ до $30 \mu \mathrm{m}$.

\section{Распределения длин дефектов на поверхности гранитов}

На рис. 7 показаны распределения числа $N$ струй ионов из ненапряженных и одноосносжатых образцов габбро-диабаза от их интенсивности $-I_{m}$, которая пропорциональна длине „канавок“. Видно, что распределения имеют вид $N=N_{0} \exp \left(-b I_{m}\right)$, где $N_{0}-$ предельное значение $N$ при $I_{m} \rightarrow 0$, а $b=\ln \left(N_{0} / N\right) / I_{m}$. Такой же вид имели распределения для аляскита и плагиогранита. Это означает, что число „канавок“ экспоненциально уменьшается при увеличении их длины.

В таблице приведены значения $\ln N_{0}$ и $b$ для габбро-диабаза и аляскита. Видно, что величина $\ln N_{0}$ слабо зависит от напряжения, а $b-$ растет при его увеличении. Это показывает, что сжимающее напряжение тем сильнее подавляет выход дефектов на поверхность, чем больше их длина.

\section{Заключение}

Под влиянием ударной волны на поверхность гранитов выходят дислокации, двигающиеся в пересекающихся плоскостях скольжения. Кристаллическая решетка в областях пересечения плоскостей сильно искажена, поэтому ударная волна вызывает испарение положительно заряженных ионов из таких областей [12]. После испарения на поверхностях гранитов образуются дефекты, которые имеют вид протяженных „канавок“. Сжимающая нагрузка подавляет процесс образования таких дефектов.

Работа выполнена при финансовой поддержке Российского фонда фундаментальных исследований (грант № 16-05-00138). 


\section{Список литературы}

[1] Веттегрень В.И., Воронин А.В., Куксенко В.С., Мамалимов Р.И., Щербаков И.П. // ФТТ. 2014. Т. 56. Вып. 2. C. 315-317. [Vettegren V.I., Voronin A.V., Kuksenko V.S., Mamalimov R.I., Shcherbakov I.P. // Phys. Solid State. 2014. Vol. 56. N 2. P. 317-320.] doi: 10.1134/S1063783414020322

[2] Веттегрень В.И., Щербаков И.П., Воронин А.В., Куксенко В.С., Мамалимов Р.И. // ФТТ. 2014. Т. 56. Вып. 5. C. 981-985. [Vettegren V.I., Shcherbakov I.P., Voronin A.V., Kuksenko V.S., Mamalimov R.I. // Phys. Solid State. 2014. Vol. 56. N 5. P. 1018-1022.]

doi: $10.1134 / \mathrm{S} 1063783414050321$

[3] Веттегрень В.И., Щербаков И.П., Куксенко В.С., Мамалимов Р.И. // ФТТ. 2014. Т. 56. Вып. 9. С. 17671771. [Vettegren V.I., Shcherbakov I.P., Kuksenko V.S., Mamalimov R.I. // Phys. Solid State. 2014. Vol. 56. N 9. P. 1828-1832.] doi: 10.1134/S1063783414090303

[4] Веттегрень В.И., Куксенко В.С., Щербаков И.П. // Физика Земли. 2016. № 5. С. 134-149. [Vettegren V.I., Kuksenko V.S., Shcherbakov I.P. // Izvestiya, Phys. Solid Earth. 2016. Vol. 52. N 5. P. 754-769.] doi: $10.1134 / \mathrm{S} 106935131604011 \mathrm{X}$

[5] Щербаков И.П., Веттегрень В.И., Мамалимов Р.И., Махмудов Х. // ФТТ. 2017. Т. 59. Вып. 3. С. 556558. [Shcherbakov I.P., Vettegren V.I., Mamalimov R.I., Makhmudov Kh.F. // Phys. Solid State. 2017. Vol. 59. N 3. P. 575-577.] doi: 10.1134/S1063783417030295

[6] Щербаков И.П., Веттегрень В.И., Мамалимов Р.И., Махмудов Х. // ЖТФ. 2017. Т. 87. Вып. 8. С. 11821184. [Shcherbakov I.P., Vettegren V.I., Mamalimov R.I., Makhmudov Kh.F. // Techn. Phys. 2017. Vol. 62. N 8. P. 11941196.] doi: 10.1134/S1063784217080242.

[7] Щербаков И.П., Веттегрень В.И., Мамалимов Р.И., Махмудов Х. // ЖТФ. 2017. Т. 87. Вып. 10. С. 15271531. [Shcherbakov I.P., Vettegren V.I., Mamalimov R.I., Makhmudov Kh.F. // Techn. Phys. 2017. Vol. 62. N 10. P. 1533-1537.] doi: 10.1134/S1063784217100218

[8] Регель В.Р., Слуцкер А.И., Томашевский Э.Е. Кинетическая природа прочности твердых тел. М.: Наука, 1974. $560 \mathrm{c}$.

[9] Абрамова К.Б., Щербаков И.П., Русаков А.И. // ЖТФ. 1999. Т. 69. Вып. 2. С. 137-140. [Abramova K.В., Shcherbakov I.P., Rusakov A.I. // Techn. Phys. 1999. Vol. 44. N 2. P. 259-261.] doi: $10.1134 / 1.1259298$

[10] Зайдель А.Н., Прокофьев В.К., Райский С.М., Славный В.А., Шрейдер Е.Я. Таблицы спектральных линий. Изд. 4-е. М.: Наука, 1977. 800 c. [Zaidel' A.N., Prokof'ev V.K., Raiskii S.M., Slavnyi V.A., Shreider E.Ya. Tables of spectral lines. NY: Springer Science + Business Media, 1970. 782 p.]

[11] Zakrevskii V.A., Shuldiner A.V. // Phil. Mag. B. 1995. Vol. 71. N 2. P. $127-138$.

[12] Владимиров В.И. Физическая природа разрушения металлов. М.: Металлургия, 1984. 280 с. 